\title{
ENGENHARIA DE PRODUÇÃO NO BRASIL: REFLEXÕES ACERCA DA ATUALIZAÇÃO DOS CURRÍCULOS DOS CURSOS DE GRADUAÇÃO
}

\author{
ENGINEERING PRODUCTION IN BRAZIL: REFLECTIONS \\ CONCERNING THE UPDATE OF THE RESUMES OF THE \\ UNDERGRADUATE COURSES
}

\begin{abstract}
Egidio Luiz Furlanetto ${ }^{1}$; Henri Geraldo Malzac Neto ${ }^{2}$; Cleiber Pereira Neves ${ }^{3}$
${ }^{1}$ Federal University of Campina Grande - UFCG - Campina Grande - Brasil elfurlanetto@terra.com.br ${ }^{2}$ Federal University of Campina Grande - UFCG - Campina Grande - Brasil hmalzac@gmail.com

${ }^{3}$ Federal University of Campina Grande - UFCG - Campina Grande - Brasil cleiber@gmail.com
\end{abstract}

\begin{abstract}
Resumo
O presente artigo tem por objetivo apresentar uma reflexão acerca da atualidade dos conteúdos abordados nos diferentes currículos dos cursos de graduação em Engenharia de Produção no Brasil. Para tal, foram tomados por base quatro grandes temas considerados transversais e atuais para a formação dos engenheiros em geral e, especialmente, dos engenheiros de produção, sendo eles: Gestão da Inovação, Ética e Responsabilidade Social, Gestão Ambiental $e$ Empreendedorismo. Devido às características próprias do curso de engenharia de produção o artigo procura, ainda, identificar a carga horária média dedicada aos componentes curriculares específicos de administração, procurando compará-la entre as diferentes ênfases. A metodologia utilizada consistiu-se de uma pesquisa às páginas oficiais dos cursos de Engenharia de Produção vigentes no Brasil em 2005. No total, foram pesquisadas 42 instituições e a amostra foi constituída de 48 cursos, tendo em vista que duas instituições de ensino superior possuem mais de uma ênfase, o que representou aproximadamente 25\% dos 188 cursos registrados no INEP em 2005. Como resultado da pesquisa, é possível concluir-se que, em geral, os quatro temas selecionados estão sendo tratados de forma muito tímida pelos diferentes cursos que compõem a amostra da presente pesquisa, deixando uma primeira impressão de que os cursos, por meio de suas estruturas curriculares, não estão conseguindo acompanhar a rápida evolução que ocorre com a sociedade em geral e, em especial, com o mercado.
\end{abstract}

Palavras-chave: educação; engenharia de produção; cursos de graduação.

\section{Introdução}

Segndo a Associação Brasileira de Engenharia de Produção (ABEPRO, 2006), compete à Engenharia de Produção o projeto, a implantação, a operação, a melhoria e a manutenção de sistemas produtivos integrados de bens e serviços, envolvendo homens, materiais, tecnologia, informação e energia. Compete à Engenharia de Produção, ainda, especificar, prever e avaliar os resultados obtidos destes sistemas para a sociedade e o meio ambiente, recorrendo a conhecimentos 
especializados da matemática, física, ciências humanas e sociais, conjuntamente com os princípios e métodos de análise e projeto de engenharia.

A Engenharia de Produção, ao enfocar as dimensões do produto e do sistema produtivo, veicula-se fortemente com as idéias de planejar a produção, projetando e viabilizando produtos e sistemas produtivos segundo as exigências das demandas que a sociedade atual é impingida a valorizar. A Engenharia de Produção guarda em seu bojo a habilidade de poder integrar de forma profunda e profissional estas atividades essenciais para a elevação de qualquer contexto onde a competitividade seja um aspecto a ser valorizado.

Além disso, pode-se afirmar que parte das atividades do Engenheiro de Produção tem se voltado para o processo de organização e administração dos recursos na produção de bens e serviços. Assim, cabe a ela também, uma missão mais ampla, a de estabelecer as relações entre os fatores da relação homem-máquina e especial atenção deve ser dada ao homem enquanto participante do processo de produção e enquanto futuro usuário ou proprietário do bem ou serviço produzido. Por outro lado, cada vez mais, necessita-se tomar decisões dentro de uma visão sistêmica, onde diversos fatores concorrem de modo integrado para que se faça a escolha adequada visando conseguir a máxima eficiência técnica com a máxima eficiência financeira.

Portanto, os avanços tecnológicos, os quais, paradoxalmente, em vez de acentuarem as tendências para a superespecialização, acabaram revertendo este quadro no sentido de permitirem níveis adequados de integração de sistemas, exigindo profissionais com ampla habilitação nas técnicas e nos princípios da Engenharia de Produção. Com isso, altera-se significativamente o conteúdo e as habilidades esperadas da mão-de-obra em termos mundiais e essas mudanças têm se refletido fortemente na realidade e nas perspectivas profissionais do engenheiro de produção. Ou seja, a formação dos futuros profissionais deve possibilitar que uma gama muito grande de temascomponentes seja oferecida nos mais diferentes currículos dos cursos de Engenharia de Produção.

Dentro desse contexto, o presente artigo tem por objetivo avaliar até que ponto alguns temas-componentes considerados transversais e atuais estão sendo trabalhados nos cursos brasileiros de Engenharia de Produção. Desta forma, por meio de pesquisa realizada junto ao site de 48 cursos vigentes no Brasil no ano de 2005, procurou-se identificar as seguintes questões: primeiramente, o número de cursos com formação plena e habilitações, bem como a carga horária dos mesmos; em segundo lugar, procurou-se identificar a carga horária relativa aos conteúdos de administração para, com isso, tentar estabelecer um paralelo entre os cursos de formação plena e os com habilitações e; finalmente, fazer uma análise comparativa, tomando como referência quatro grandes temas-componentes, considerados importantes e atuais, a saber, Gestão da Inovação, Ética e Responsabilidade Social, Gestão Ambiental e Empreendedorismo. 
Assim sendo, o artigo está composto da seguinte forma: além de seu resumo e de sua introdução, de uma seção onde se aborda a Engenharia de Produção e o ensino da mesma no Brasil; da metodologia utilizada; da apresentação e análise dos resultados e; por último, das conclusões e referências.

\section{Engenharia de Produção}

Foi na chamada Engenharia Industrial do começo do século passado, que a Engenharia de Produção teve seu início, quando os pioneiros, Frank Gilbreth e Frederick Taylor, desenvolveram estudos sobre o aumento da produtividade e métodos de redução de tempos e movimentos dos operários na fabricação de peças. Taylor, apesar de ser considerado o "pai da administração" era de fato engenheiro. Os métodos desenvolvidos por ele foram posteriormente aplicados em larga escala na indústria automobilística por Henry Ford, que, introduzindo o sistema de "produção em massa" através do conceito de linha de montagem seriada, reduziu os custos de produção, elevando as taxas de produtividade e, principalmente, seus lucros. Entretanto, a partir da segunda metade do Século $\mathrm{XX}$ as, até então, empresas de produção em massa, passaram por profundas transformações, principalmente por conta das alterações ocorridas no comércio internacional. Com isso, o conhecimento estratégico e a melhoria contínua dos processos empresariais passaram a ocupar posição de destaque, fazendo-se necessário a presença de profissionais com perfis adequados a essa nova realidade.

É exatamente neste momento que o engenheiro de produção aparece como figura valorizada, visto que o mesmo é, dentre os profissionais das engenharias, um dos mais bem talhados para tal, pois, além de um conjunto de conhecimentos técnicos, relacionados às áreas de produção, qualidade, economia, produto, estratégia organizacional, conhecimento, meio ambiente, pesquisa operacional, ergonomia e segurança no trabalho, que são as subáreas de formação e atuação do engenheiro de produção, todos elas vistos de forma indissociável, a formação do engenheiro de produção privilegia, também, a área da gestão das organizações.

A Figura 1, construída por Cunha (2002), e apresentada a seguir, consegue comparar de forma clara esta interligação entre as diferentes áreas do conhecimento, em especial a relação entre a Engenharia de Produção e as outras formações.

Desta forma, o engenheiro de produção possui como característica principal a atuação na produção diretamente dita, ou seja, enquanto as outras engenharias trabalham na fase de invenção dos produtos, dos processos e da tecnologia que serão colocados em prática na produção; o engenheiro de produção entra em cena muito mais para reduzir custos e melhorar a qualidade dos 
produtos, cuidar da distribuição e da gestão dos processos produtivos de forma geral. Portanto, atuando numa interface entre as áreas das engenharias e das ciências da administração.

Figura 1 - Áreas de concentração dos cursos de Administração, Engenharias e demais cursos técnicos

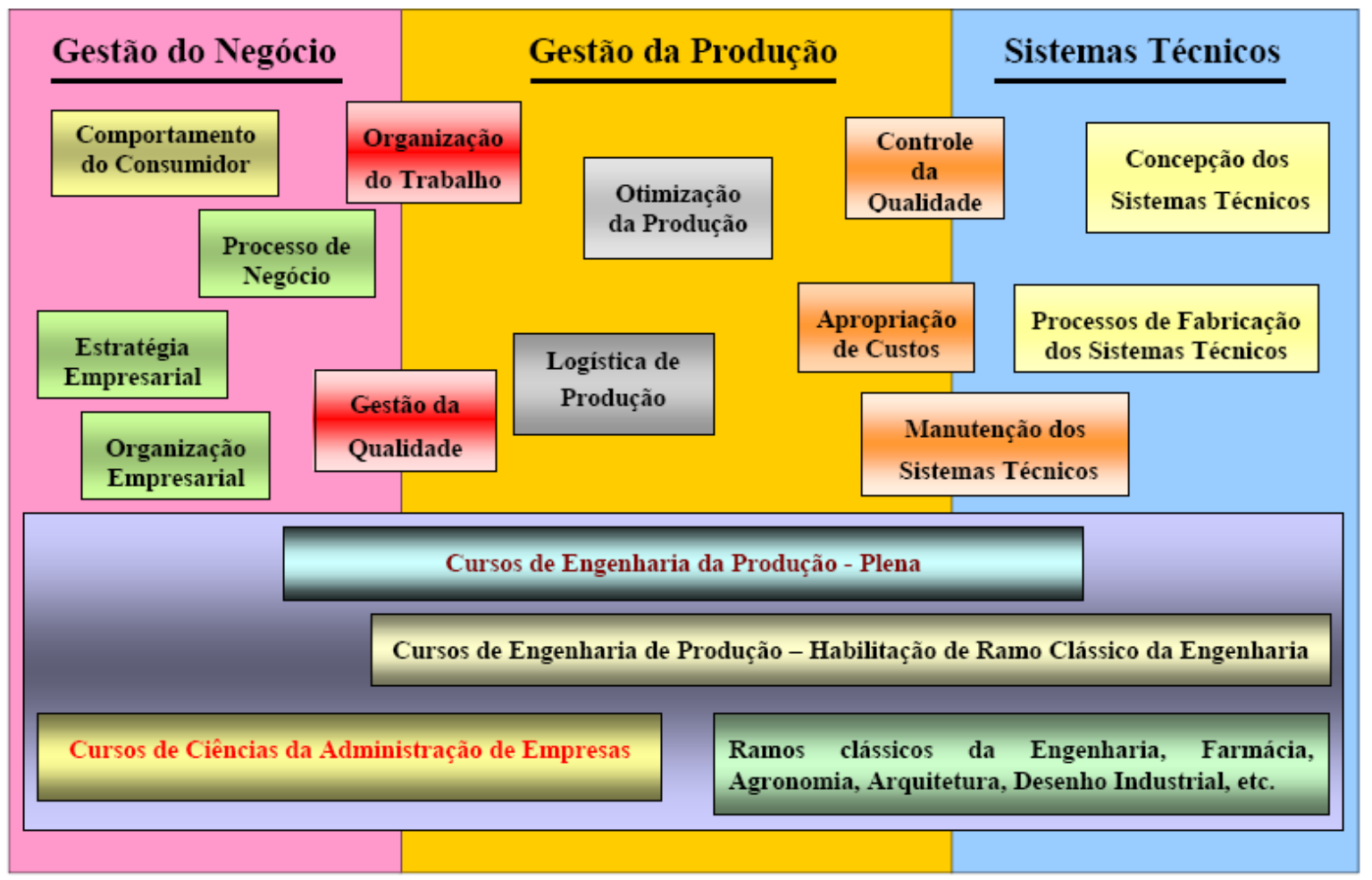

Fonte: CUNHA, 2002

Entretanto, diferentemente dos cursos de administração, onde a formação dos profissionais é concentrada mais na questão da gestão dos processos administrativos, processos de negócio e na organização estrutural da empresa, na Engenharia de Produção a formação é centrada na gestão dos processos produtivos.

\subsection{A Engenharia de Produção no Brasil}

Embora tenha sido criado nos Estados Unidos no início do Século XX com o nome de Engenharia Industrial, este novo ramo da engenharia só veio surgir, no Brasil, na década de cinqüenta, com o nome de Engenharia de Produção.

No Brasil, predominam dois tipos de cursos de Engenharia de Produção: os cursos ditos plenos e os cursos concebidos como habilitações especificas de um dos ramos tradicionais da Engenharia. Os do primeiro tipo concentram boa parte da carga horária profissionalizante no estudo da gestão da produção, enquanto que os do segundo tipo dividem essa carga entre esse estudo e o dos sistemas técnicos - normalmente, priorizando este último por larga margem. 
Portanto, a Engenharia de Produção tanto pode ser de formação plena, como ser uma habilitação específica derivada de qualquer uma das seis grandes áreas da engenharia. Assim, existem cursos de engenharia de produção elétrica, de produção civil, de produção mecânica, entre outros, conforme apresentado na Figura 2.

Figura 2 - Relação da Engenharia de Produção com as demais áreas

\begin{tabular}{|c|c|c|c|}
\hline \multirow{6}{*}{$\begin{array}{c}\text { Ciências da } \\
\text { Administração } \\
\text { de Empresas }\end{array}$} & \multirow{6}{*}{$\begin{array}{c}\text { Engenharia } \\
\text { de } \\
\text { Produção }\end{array}$} & Engenharia de Produção Civil & Engenharia Civil \\
\hline & & $\begin{array}{l}\text { Engenharia de Produção } \\
\text { Mecânica }\end{array}$ & Engenharia Mecânica \\
\hline & & Engenharia de Produção Química & Engenharia Química \\
\hline & & Engenharia de Produção Elétrica & Engenharia Elétrica \\
\hline & & $\begin{array}{l}\text { Engenharia de Produção } \\
\text { Metalúrgica }\end{array}$ & $\begin{array}{l}\text { Engenharia } \\
\text { Metalúrgica }\end{array}$ \\
\hline & & & Engenharia de Minas \\
\hline & (Plena) & $\begin{array}{c}\text { (Habilitação em ramos da } \\
\text { Engenharia) }\end{array}$ & (Ramos clássicos) \\
\hline $\begin{array}{c}\text { Formação } \\
\text { Teórica de } \\
\text { Predominância } \\
\text { Gerencial }\end{array}$ & & & $\begin{array}{c}\text { Formação Teórica de } \\
\text { Predominância } \\
\text { Tecnicista }\end{array}$ \\
\hline
\end{tabular}

Fonte: Adaptada de CUNHA, 2002

\subsection{Números da Engenharia de Produção no Brasil}

A partir de 1998 houve um crescimento vertiginoso do número de cursos de Engenharia de Produção no Brasil, saltando dos 38 registrados em 1997 para aproximadamente 200 cursos em 2005, registrando-se a criação em torno de quase 20 cursos por ano. (OLIVEIRA et. al.; 2005).

O quadro brasileiro atual aponta para um expressivo número de novos cursos e a existência de 2 modalidades de cursos: uma plena, e a outra, colocando-se como uma habilitação específica das 6 grandes áreas da engenharia.

De modo geral, é possível afirmar-se que este acréscimo significativo no número de cursos, ocorrido especialmente nos últimos anos, é devido à sua formação multidisciplinar e visão sistêmica, pois o mercado de trabalho para este profissional é amplo, sendo possível atuar nas diferentes áreas de uma organização como finanças, produção, recursos humanos, marketing ou desenvolvimento do produto.

Ainda de acordo com Oliveira et. al. (2005), atualmente verifica-se uma clara tendência para a chamada Engenharia de Produção "Plena", posicionada mais para o lado esquerdo da Figura 2, a qual possui um currículo abrangente, capaz de formar um profissional com uma visão holística e de posição extremamente valorizada no mercado atual. 


\section{Metodologia}

A metodologia de pesquisa constituiu-se de consultas às páginas oficiais na internet, tanto do INEP (www.inep.gov.br), como de Instituições de Ensino Superior que oferecem o curso de Engenharia de Produção e da Associação Brasileira de Engenharia de Produção - ABEPRO (www.abepro.org.br), bem como de dados secundários de outros trabalhos que foram desenvolvidos com o mesmo foco.

Os procedimentos seguiram a seguinte ordem: primeiramente buscou-se informações gerais junto ao site do INEP para, posteriormente, por meio do acesso às páginas oficiais das instituições pesquisadas, analisou-se cada uma das diferentes estruturas curriculares (curriculos, fluxogramas, grades curriculares ou matrizes curriculares).

No total, foram pesquisadas 42 instituições e a amostra foi constituída de 48 cursos, o que representa aproximadamente $25 \%$ dos 188 cursos registrados no INEP em 2005. A razão do número de cursos ser superior ao de instituições deve-se ao fato de que tanto a PUCRJ como a FEEVALE, ambas pesquisadas, possuem, respectivamente, seis e duas ênfases.

A relação de instituições pesquisadas foi a seguinte: EEMA, UniABC, USF, UNISC, UNISINOS, UNISUL, FEEVALE, FUMEC, UFOP, UFPB, UNITAU, UNOESC, UTFPR, FABAN, FEJAL/CESMAC, USP, PUCPR, UCS, UFMG, UFJF, CESF, FJA, UFRGS, UNESPAR, UCP, UCG, UEM, UFF, UNIFOR, FACCAT, UVV, PUCRJ, EEM, UFPE, UNIFEI, UNIFRAN, UNIP, POLI-UFRJ, UERJ, UNIPAN, FAESA e FBV.

De posse das estruturas curriculares e com o objetivo de avaliar como os diferentes cursos estão tratando alguns temas considerados imprescindíveis e atuais, devido às exigências legais e do mercado, procedeu-se a mensuração dos cursos levando-se em consideração os seguintes pontos: a) ênfases; b) carga horária total de disciplinas de administração; c) carga horária de disciplinas de Gestão Ambiental: d) carga horária de disciplinas de Gestão da Inovação; e) carga horária de disciplinas de Ética e Responsabilidade Social e; f) carga horária de disciplinas de Empreendedorismo.

\section{Apresentação e análise dos resultados}

A presente seção apresenta os dados encontrados na pesquisa e procura proceder a uma análise geral dos diferentes cursos em relação aos itens já mencionados acima, iniciando pela caracterização da amostra da pesquisa. 


\subsection{Caracterização da amostra}

O comportamento da amostra pesquisada em relação à variável ênfase pode ser visto na Figura 3 onde, dos 48 cursos analisados, a grande maioria (55\%) é composta por cursos de ênfase plena, apresentando a ênfase em Engenharia Mecânica como a segunda ênfase com maior número de cursos, com 23\%. É importante destacar que estes números estão muito próximos dos percentuais encontrados por Oliveira et. al. (2005), os quais pesquisaram todos os 188 cursos registrados no INEP em 2005 e encontraram, entre outros resultados, que do universo de cursos de Engenharia de Produção do Brasil, 53,2\% correspondem aos cursos de ênfase plena e 23,9\% aos de Engenharia Mecânica.

Figura 3 - Distribuição dos Cursos Brasileiros de Engenharia de Produção por Ênfase

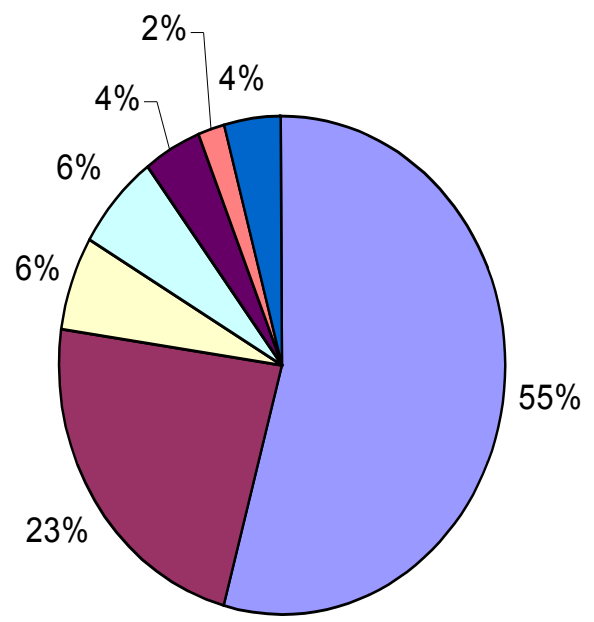

$\square$ Plena $\square$ Mecãnica $\square$ Agroindustrial $\square$ Civil $\square$ Elétrica $\square$ química $\square$ Outras

Fonte: Organizado a partir dos dados dos diferentes cursos

\subsection{Carga horária dos componentes de administração}

Devido às funções e cargos ocupados pelos Engenheiros de Produção, é de fundamental importância que os cursos incorporem em suas estruturas curriculares temas específicos de administração, especialmente por que mais da metade dos cursos brasileiros de Engenharia de Produção são da ênfase plena, isto é, significa dizer que a formação destes profissionais precisa ter uma abrangência bem maior, pois muitos deles poderão atuar nos mais diversos setores das empresas e de serviços. 
A partir da leitura da Figura 4 é possível perceber-se que 15\% dos cursos possuem até 90 horas de componentes curriculares de administração, 28\% de 120 a 180 horas, $21 \%$ de 210 a 240 horas, e 17\% possuem de 300 a 540 horas de conteúdos de administração. Percebe-se, também, que em $19 \%$ de todos os cursos que compõem a amostra não foi possível identificar a carga horária dos componentes curriculares de administração. A razão desta dificuldade deveu-se em função de que em muitos destes cursos as informações presentes na página não deixavam claro como ocorre a escolha, por parte do aluno, no momento da matrícula. Portanto, somente foram considerados os conteúdos de caráter obrigatório.

Por outro lado, e conforme já era esperado, devido à abrangência de cada uma das ênfases, entre os cursos da ênfase plena a média da carga horária dos componentes de administração é de 212 horas, enquanto a média do cursos com outras ênfases é de 180 horas, indo de encontro, mais uma vez, com que é apresentado na Figura 2, isto é, e via de regra, a medida que ocorre o deslocamento para a esquerda da mencionada figura as cargas horárias dos conteúdos de administração aumentam.

Figura 4 - Carga horária dos componentes de administração dos Cursos de Engenharia de Produção

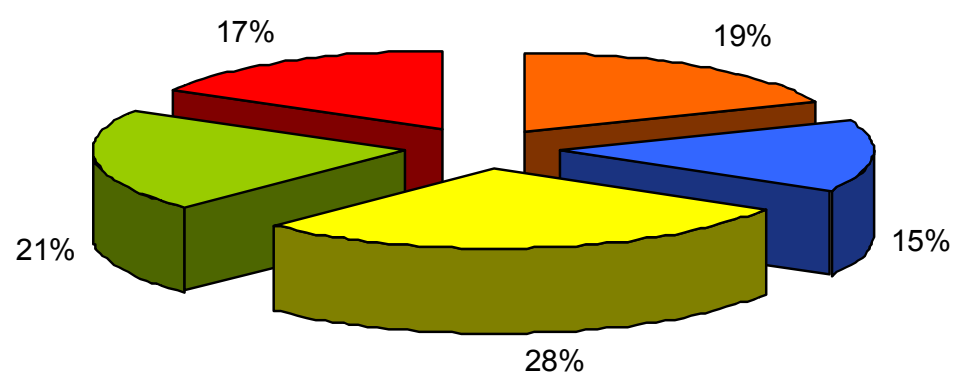

\begin{tabular}{|lll|}
\hline$\square$ Não informado & $\square$ De 60 a $90 \mathrm{~h}$ & $\square$ De 120 a $180 \mathrm{~h}$ \\
$\square$ De 210 a $240 \mathrm{~h}$ & $\square$ De 300 a $540 \mathrm{~h}$ & \\
\hline
\end{tabular}

Fonte: Organizado a partir dos dados dos diferentes cursos

\subsection{Carga horária dos componentes de Empreendedorismo}

Dos 48 cursos pesquisados, foi possível identificar que somente 16 deles $(33,33 \%$ do total pesquisado) possuem componentes de empreendedorismo em suas estruturas curriculares, o que representa muito pouco se levando em consideração a importância do tema e a própria realidade do mercado de trabalho. Destes 16 cursos, quatro possuem de 30 a 45 horas, nove deles possuem 60 horas e três possuem de 75 a 90 horas dedicadas ao ensino do tema. 
As percentagens relativas a estes cursos podem ser vistas na Figura 5, apresentada a seguir.

Figura 5 - Carga Horária de Empreendedorismo dos Cursos de Engenharia de Produção

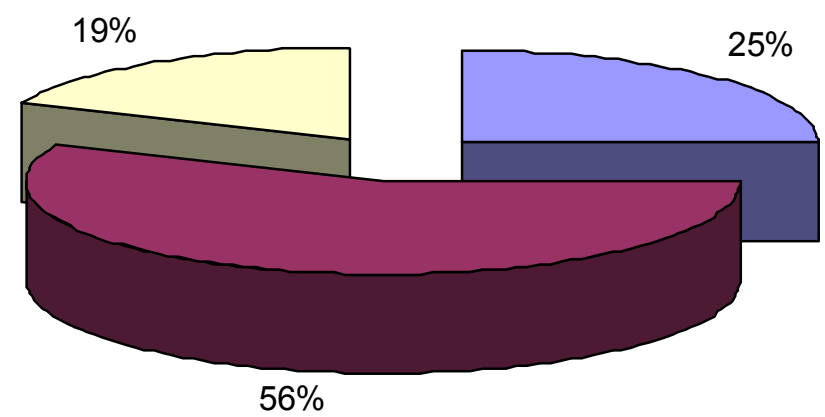

$\square$ De 30 a $45 \mathrm{~h} \square$ De $60 \mathrm{~h} \square \operatorname{De} 75$ a $90 \mathrm{~h}$

Fonte: Organizado a partir dos dados dos diferentes cursos

\subsection{Carga horária dos componentes de Gestão da Inovação}

Entre os 48 cursos consultados, somente oito apresentam em sua estrutura curricular carga horária específica para tratar do tema gestão da inovação e da tecnologia, ou seja, apenas $16,66 \%$ do total dos cursos oferecem, em média, uma carga horária de $60 \mathrm{~h}$ destinada exclusivamente a esse tema o que, em princípio, representa muito pouco levando-se em consideração a relevância do tema. É importante lembrar que a inovação é vista como a chave para a competitividade das empresas.

Portanto, muito embora o ambiente esteja a exigir das empresas e, em última análise dos próprios engenheiros de produção, constantes mudanças nos produtos e processos, o que se pode apurar é que as estruturas curriculares estão um pouco distante dessa realidade de mercado, principalmente no atual momento em que o Governo acaba de lançar a Lei da Inovação e a nova Política Indústrial, Tecnológica e de Comércio Exterior - PITCE.

\subsection{Carga horária dos componentes de Gestão Ambiental}

Gestão Ambiental é outro tema de importância, e atual na formação dos futuros engenheiros, haja vista que o mesmo assume graus elevados de relevância, tanto no momento da abertura de um novo empreendimento, como durante seu funcionamento, em virtude dos possíveis danos ambientais provocados pelos mais diferentes processos produtivos. É sempre bom lembrar que, ao longo dos tempos as indústrias foram, via de regra, vistas como vilãs neste processo e, segundo muitos especialistas, ainda possuem um passivo a ser explorado. 
Portanto, em relação aos componentes curriculares de Gestão Ambiental constata-se que somente 17 dos 48 cursos pesquisados possuem componentes curriculares específicos do tema, isto é, em apenas $35,47 \%$ do total dos cursos da amostra pesquisada eles estão presentes.

Foi possível observar-se, ainda, que dos 17 cursos que incluíram carga horária específica para Gestão Ambiental, cinco deles $(10,41 \%$ da amostra total) exigem até 45 horas dedicadas ao tema, enquanto que outros 12 (25\% do total da amostra) exigem entre 60 a 75 horas exclusivas ao tema.

\subsection{Carga horária dos componentes de Ética e Responsabilidade Social}

A importância do tema Ética e Responsabilidade Social tem crescido nos últimos tempos, a ponto de estar incluído entre as características que acabam identificando uma empresa e, com isso, conferindo-lhe competências, principalmente no tocante a imagem da mesma perante a sociedade. Neste sentido, existe, ainda, toda uma obrigatoriedade legal que vem sendo "imposta" às empresas no que diz respeito a sua responsabilidade com o ambiente em que a mesma estiver inserida.

Entretanto, a partir da pesquisa foi possível identificar que, em relação aos componentes curriculares de Ética e Responsabilidade Social, somente 18 dos 48 cursos, ou seja, 37,5\% do total da amostra possuem em suas estruturas curriculares carga horária exclusiva para o tema. Destes 18 cursos, quatro possuem até 45 horas, 11 deles possuem 60 horas, e três possuem de 90 a 120 horas de aulas dedicadas ao assunto.

\section{Conclusões}

Antes de qualquer conclusão e, embora a amostra pesquisada tenha sido altamente representativa do universo, é importante que sejam feitas algumas ressalvas: a primeira delas diz respeito ao fator limitador da pesquisa, uma vez que muitas informações, que talvez pudessem alterar, em parte, o quadro apresentado, podem não terem sido disponibilizadas nos respectivos sites oficiais, é tanto que a segunda fase da pesquisa se dedicará em avaliar esta questão em detalhas, enviando questionários a todas as instituições; a segunda ressalva diz respeito ao fato de que foram analisados somente os componentes curriculares (as comumente denominadas disciplinas) de caráter obrigatório, com isso, possíveis conteúdos relacionados com os temas selecionados podem estar sendo vistos em componentes curriculares que, aparentemente, não têm relação direta com os temas avaliados e, portanto, não foram idenficados na presente pesquisa. Neste sentido, é bom lembrar, também, que as exigências das Diretrizes Curriculares do MEC mencionam somente os mais diferentes conteúdos, ficando a cargo de cada instituição a forma de como abordá-los, isto é, muitas instituições podem apresentar estes conteúdos em componentes curriculares com os mais 
diversos nomes, o que acaba dificultando sua identificação em pesquisas desse tipo.

Feitas as ressalvas, é possível concluir-se que, em geral, os quatro temas selecionados estão sendo tratados de forma muito tímida pelos diferentes cursos que compõem a amostra da presente pesquisa, deixando uma primeira impressão de que os cursos, por meio de suas estruturas curriculares, não estão conseguindo acompanhar a rápida evolução que ocorre com a sociedade em geral e, em especial, com as empresas, podendo provocar problemas no médio e longo prazo, quando seus egressos forem inseridos no mercado de trabalho.

Muito embora existam boas exceções, números como os encontrados em relação ao oferecimento dos componentes curriculares de Empreendedorismo e Gestão da Inovação são alarmantes, principalmente no atual momento, no qual boa parte dos futuros egressos "forçosamente" terá que empreender, ou pelo menos apresentar o comportamento, ou a atitude de um empreendedor frente às dificuldades da vida profissional e até mesmo particular de cada um deles. Parece claro de que, uma vez iniciados neste processo quando ainda estão nos bancos universitários, as possibilidades de sucesso no mercado de trabalho dos atuais alunos de graduação poderão ser ampliadas.

Os outros dois temas selecionados, Gestão Ambiental e Ética e Responsabilidade Social, os quais estão de certa forma interligados, também apresentaram números pouco expressivos para a realidade das organizações. Os números da pesquisa indicam que, em ambos os temas, somente cerca de um terço dos cursos avaliados possuem componentes curriculares específicos para tratar dos mesmos.

Desta forma, os números da pesquisa, embora com seus fatores limitantes podem, pelo menos servir de inspiração para que os mais diferentes educadores, em qualquer uma das Instituições de Ensino Superior do Brasil que oferecem os Cursos de Engenharia de Produção, passem a analisar e refletir acerca da atualidade dos Projeto Político Pedagógico de seus cursos, o que, em última análise vai de encontro às recomendações das próprias Diretrizes Curriculares do MEC. Neste sentido, é importante lembrar que esta discussão pode ser feita, também, via participação junto aos fóruns da ABEPRO, bem como aos ENCEP's (Encontro Nacional de Coordenadores de Cursos de Engenharia de Produção), os quais ocorrem com periodicidade anual e conseguem reunir uma parcela considerável de profissionais da área. 


\begin{abstract}
The present article's objective is to present a reflection concerning the present time of the contents approached in the different degree courses in Engineering of Production at Brazil. For such, they were taken by base four great themes considered traverse and current for the engineers' formation in general and, especially, of the production engineers, being them: Administration of the Innovation, Ethics and Social Responsibility, Environmental Administration and Entrepreunership. Due to the own characteristics of the course of production engineering the article seeks, still, to identify the medium workload dedicated to the components specific of administration, trying to compare among her the different emphases. The used methodology was consisted from a research to the official pages of the effective courses of Engineering of Production of Brazil in 2005. In the total, they were researched 42 institutions and the sample was constituted by 48 courses, tends in view that two higher education institutions possess more than an emphasis, what represented $25 \%$ of the 188 courses approximately registered in INEP in 2005. As a result of the research, it is possible to end that, in general, the four selected themes are being treated in a very shy way by the different courses that compose the sample of the present researches, leaving a first impression that the courses, through their curricular structures, they are not getting to accompany the fast evolution that happens with the society in general and, especially, with the market.
\end{abstract}

Key-words: education; production engineering; undergraduate course.

\title{
Referências
}

ABEPRO - Associação Brasileira de Engenharia de Produção, www.abepro.org.br, último acesso em 26 de maio de 2006.

CUNHA, G. D. Um Panorama da Engenharia de Produção. Porto Alegre, 2002, disponível no site da ABEPRO, www.abepro.org.br.

INEP. Instituto Nacional de Estudos e Pesquisas Educacionais, www.inep.gov.br, último acesso em 26 de maio de 2006 .

MEC/CNE/CES. Diretrizes Curriculares para os Cursos de Graduação em Engenharia. Resolução CNE/CES. Brasília, 11 de Março de 2002.

OLIVEIRA, V. F.; BARBOSA C. S. \& CHRISPIM E. M. Cursos de Engenharia de Produção no Brasil: Crescimento e Projeções. Anais do XXV Encontro Nac. de Engenharia de Produção. Porto Alegre, RS, Brasil, 29 out a 01 de nov de 2005.

\section{Dados dos autores:}

Egidio Luiz Furlanetto

Universidade Federal de Campina Grande - UFCG

Unidade Acadêmica de Engenharia de Produção

Rua Júlio Ferreira Tavares 289 - Catolé - Campina Grande - PB - 58105-048

Telefones para contato: 83 - 33101041

e-mail: elfurlanetto@terra.com.br 
Henri Geraldo Malzac Neto

Universidade Federal de Campina Grande - UFCG

Engenharia de Produção

Cristo Redentor, João Pessoa, Paraíba, Brasil, 58071-280.

Telefones: (083) 3223.4345 / (083) 8818.1206

e-mail: hmalzac@gmail.com

Cleiber Pereira Neves

Universidade Federal de Campina Grande - UFCG

Departamento: Engenharia de Produção

Santa Cruz, Campina Grande, Paraiba, 5810-000

Telefones: (083) 3335.2925 - (083) 8838.5232

e-mail: cleiber@gmail.com

Recebido para publicação em: 20/10/2006

Aceito para publicação em: 25/11/2006 